\title{
Drawing as a Periphery in Architectural Learning
}

\author{
ANA LEONOR M. MADEIRA RODRIGUES \\ Universidade Lusiada \\ Portugal
}

\begin{abstract}
Drawing is a discipline where feelings and emotions may be used as a creative "scientific" tool subversively unbalancing the power structures.
\end{abstract}

The conquest of a dominant place over the members of the same race, with the result of using the power such a place allows and having the acceptance of the other members for being the leaders is a characteristic of the adult relationship between almost all animal species.

The former time of childhood was dedicated to the imitation of the adults and to the experimenting of behaviors, or, in other words, learning and playing.

Humberto Maturama believes that humans are, in behavioral terms, an exception, as the time of childhood is extended throughout most adult life, which defines us humans as a neotenic race, and with the use of other behaviors, we have transformed what is the usual master/slave relation of adult members from other races. Like this, the family in the way we live it, becomes a human invented structure that implies relationships between its members which are bounded by mutual trust and love. Mutatis mutandis we spend our life repeating relationships that use the same pattern. In this way, love would be the main engine of evolution and also our greatest invention.

However, there are other behavioral structures that rather mimic the adult life of other primates than this golden age of human childhood; this makes us think about the use and abuse of power as a perverted behavior and who knows, an inability of interacting at a more biologically human level.

Besides, humans may elude this perversion with the most varied inventions and vindications, but the uses and abuses of power make such an intricate design with our lives that probably the only way to avoid it is by being subversively human.

Teaching and what is more, teaching as part of an institutional structure, is precisely to transmit to the students those same structures of power through the metaphoric situation: the one who teaches has the power of detaining more knowledge that the one who is learning and so, the power to arbitrary decide about what will be learned.

The problem "what is teaching" unveils another question which is: what is being taught has to do with knowledge (an understanding in depth), or has it to do with information (an understanding in extension)? Particularly with architecture we usually have another problem which is to define the more artistic/humanistic or more technical/scientific character of this Art. The tendency to learn by dividing and dissecting is an attitude that defined very well our scientific mind. We kill to understand, we divide to reign and from annihilation to annihilation we reach a schizophrenia that conditions us to such an extent that we are unable to think about other ways of doing it.

In the curricula of artistic subjects, there is a very discreet discipline that with diplomacy and some subversion, makes a detour to these problems: drawing. Drawing is a place for knowledge, for precision, but also for feelings and emotions. Going further one can say that feelings and emotions are a specific tool of the discipline. More and more the understanding of mind activity, acknowledges emotions as one of the main instruments for thinking and for helping us to survive as individuals inside the group.

Drawing has the quality of mobilizing feelings in a very particular way, inseparable from intelligence as well as other functions of the mind; and when it assumes emotions as an instrument of learning, it moves the act of learning to an area which is different from the usual discursive logic, without loosing precision or scientific qualities.

As imitation and play are the main ways to learn, drawing from life is a technic that using those actions directly, teaches in the proper action and moment of doing it.

The omnipotence of the one detaining the knowledge is annilated and in this subtle way it becomes a deeply antipower activity. Also, either by direct use or by extrapolation it is a way of discovering in oneself the process of being creative and how to use it. With any person who is drawing, sooner or later happens this "clic" -I've got it - of absolute clarity of discovering how to use the technic and from then on it is just a question of exercising, inside oneself and with the paper, how to use this language.

In the specific case of Architecture, drawing becomes crucial not only because of the education it implies, not only because of the very particular way of thinking it produces so 
close to the architectural thinking, but because it removes the process of learning to the one who is learning. When it forces the look to the others and the outside, it establishes a real contact with the world where architecture is being built and with the inhabitants of this architecture.

Students curricula include more and more space dedicated to the learning of computer assisted solutions, which, in itself raises no particular problem, if it was not for the fact that it imprints a very abstract and inhuman manner of thinking about building, which quite often ignores the aim of architecting; to build for the humans to inhabit or use it.However, lobbies of political, cultural or economical power, turn aside this aim to others that seem to become the true reason to make architecture: to make good profit in real estate business, to look dashing in some glossy magazine or to integrate, reconstruct, disintegrate physical abstractions over the surface of the Earth.

But will this same power allow that the one who builds has the time to look at himself or at the inhabitant of these constructions? If, as individuals we produce marks over surfaces and call them drawings, as a group we have been printing a macroscopic and endless drawing over the surface of the Earth to which we call Architecture. Architecture is to Gaia what a tattoo is to our skin, they are drawings, scars. Cicatrization results from the regeneration process of the skin, and we may have any kind of marks, from the tattoos with their artistic/mundane/mystic intention, to accidental marks from accidental cuts; from the minimal almost perfect lines of plastic surgery to the terrifying traces of diseases. Cicratization may happen by accident or by treatment. To the first we call abandon and to the second we call restauring. Scars as well as monuments may be refereed to as marks.
Architecture is the scaring process happening over the surface of the earth, it is a huge design we go on making for the generations to come which they will call memories or monuments; Gaia's wrinkles or scars.

Drawing, besides those subversive and interesting aspects, is an hybrid discipline, as it is at the same time a very complex mental process but also a very spontaneous almost instinctive one. It is a way of seeing, learning, registering and collecting information about the visual world. Information means literally in-printing, we imprint the brain with information and impressions. We draw in the brain several maps of information. Over the paper we draw what we understand and invent from what we see, that is, we go on making scars over it.

The image of scar tissue goes deeper in the parallel with drawing, as it is not only the play of lines and shapes, it is not just a game with a random factor. It is also the violent inclusion of emotions and feelings in all this process.

Drawing or by extension, all creative process takes feelings and emotions as an embodied part of it, as an essential working tool. When I think of drawing, I think of it as any other artist may think about it. As for the straight lines the perfect perspectives, the coding of shapes, we do have may computer assisted solutions, dictionaries and endless files of usable forms.

But the inner discipline, the deep human knowledge and the exercise of freedom that makes the architect an artist is then possible through the use of drawing. Such materialization of the human spirit, as is the case with drawing, give the geographies of power a very unhealthy unbalance, it is intelligence grown into sensibility, it is the inclusion of a round and organic harmony in a in-organic and orthogonal world. 